\title{
PENGARUH PENERAPAN INTERACTIVE LECTURE DEMONSTRATION (ILD) BERORIENTASI CONCEPTUAL CHANGETERHADAP PENINGKATAN PEMAHAMAN KONSEP SISWA SMP PADA MATERI HUKUM NEWTON
}

\author{
Y. Kurniawan \\ Guru SMP Negeri Kabupaten Pandeglang \\ E-mail: yudikurniawan1012@gmail.com
}

\begin{abstract}
ABSTRAK
Latar belakang penelitian ini dilakukan karena pentingnya pemahaman konsep bagi siswa dalam mempelajari Ilmu Pengetahuan Alam (IPA), khususnya pembelajaran Fisika. Penelitian ini bertujuan untuk mendapatkan gambaran tentang perbedaan peningkatan pemahaman konsep siswayangmendapatkan pembelajaran ILD berorientasi conceptual change (CC)dibandingkan dengan peningkatan pemahaman konsep siswa yang mendapatkanpembelajaran ILD berorientasi common sense (CS)pada materi Hukum Newton. Penelitian ini berupa penelitian kuasi eksperimen dengan desain pretest-posttest control group design yang dilakukan pada kelas IX di sebuah SMP Negeri di Kabupaten Pandeglang. Hasil uji statistik menunjukkan bahwa peningkatan pemahaman konsep siswa yang mendapatkan pembelajaran ILD berorientasi CC $(<\mathrm{g}>0.42)$ pada materi Hukum Newton lebih signifikan dibandingkan peningkatan pemahaman konsep siswa yang mendapatkan pembelajaran ILD berorientasi CS (<g $>0.32)$ pada materi Hukum Newtondengan kategori sedangpada taraf signifikansi 5\%.
\end{abstract}

Kata kunci: Hukum Newton, ILD berorientasi CC, ILD berorientasi CS, pemahaman konsep

\section{ABSTRACT}

The background of this research because ofthe importance of conceptual understanding in science learning for students especially on learning physics. This research was aim to describe the difference of the increasing students' conceptual understanding who applied ILD oriented conceptual change (CC) with theincreasing of students' conceptual understanding who applied ILD oriented common sense (CS) on Newton's Laws concepts. This research was quasi-experimentalresearch with pretest-posttest control group design. The samples were $9^{\text {th }}$ grade on junior high school on Pandeglang regency. The result of statistic had shown that the increasing of students 'conceptual understanding who applied ILD oriented CC $(<g>0.42)$ had significant than students' conceptual understanding who applied ILD oriented CS $(<g>0.32)$ on Newton's Laws concepts with medium category on significance $5 \%$.

Keywords: conceptual understanding, ILD oriented CC, ILD oriented CS, Newton's Laws.

\section{PENDAHULUAN}

Melalui pembelajaran IPA, siswa diharapkan mampu menerapkan konsep yang dimilikinya untuk menyelesaikan permasalahannya sehari-hari (Permen. No.22, 2006). Penerapan konsep yang baik dan benar diawali dengan pemahaman konsep yang baik dan benar pula.Kemampuan pemahaman konsep harus mencakup semua pokok bahasan materi termasuk pokok bahasan materi yang bersifat abstrak. Oleh karena itu, terdapat kemungkinan kesulitan siswa dalam memahami suatu materi yang abstrak sebagai pemicu terjadinya kesalahan konsep, yang kemungkinan mengandung miskonsepsi (Wulandari dkk., 2013). Dengan demikian, siswa diharapkan mampu menyelesaikan permasalahan sederhana yang berhubungan dengan kehidupan sehari-hari (Setyawan, 2012).

Akan tetapi, fakta di lapangan tidak selalu demikian. Dalam kegiatan proses pembelajaran di sekolah, tidak semua siswa memahami materi pelajaran dengan baik. Hal itu disebabkan karena siswa mengalami kesulitan yang beragam sehingga perlu diberikan program perbaikan berupa pengajaran maupun bimbingan. Salah satu faktor yang menyebabkan siswa kesulitan dalam pembelajaran diantaranya karena pemahaman konsep yang rendah dan adanya miskonsepsi (Ischak dkk, 1987). 
Jika rendahnya pemahaman konsep siswa dikarenakan adanya miskonsepsi maka miskonsepsi itu harus segera diatasi. Pembelajaran yang dilakukan harus mengarah pada perubahan konseptual. Perlakuan yang digunakan dalam rangka perubahan konseptual dapat dilakukan dengan berbagai teknik dan model pembelajaran atau gabungan keduanya (Çepni, et.all: 2010).

Dalam rangka menciptakan perubahan konseptual pada siswa, maka pembelajaran harus membuat siswa aktif belajar merancang suatu teks bacaan, dialog, diskusi, dan berbagi pengalaman. Belajar merupakan suatu aktivitas menghubungkan suatu konsepdengan fenomena yang telah dimiliki. Dengan demikian, pemahaman siswa akan menjadi lebih luas. (Suparno, 2012).

Berdasarkan penjelasan tersebut, pembelajaran dikelas harus dirancang untuk membangun konsep siswa. Salah satu pembelajaran yang dapat membangun konsep siswa adalah pembelajaran konstruktivis. Pembelajaran konstruktivis mampu meningkatkan pengetahuan siswa dan membangun kemampuannya sendiri (Joyce, et.all., : 2009).

Oleh karena itu, pembelajaran yang dipilihdalam penelitian ini berupa Interactive Lecture Demonstration (ILD) berorientasi conceptual change (CC). ILD berorientasi CC dipilih karena pembelajaran ILD dapat melibatkan siswa dalam jumlah yang besar namun tetap efektif untuk meningkatkan pemahaman konsep siswa dalam berbagai konsep fisika, salah satunya mekanika (Hukum Newton) (Mazzolini, et.all., 2010).

Adapun langkah pembelajaran ILD berorientasi CC diadaptasi dari Sokoloff dan Thornton (Zimrot,et.all., 2007). Langkah pembelajaran tersebut menjadi: (1) Guru menjelaskan pada kelas rancangan demonstrasinya dan apa yang akan dilakukan; (2) Siswa menuliskan jawaban mereka pada Lembar Konsepsi dan menuliskan keyakinan mereka atas jawaban yang telah ditulis; (3) Guru melakukan demonstrasi berdasarkan kesalahan konsep siswa yang telah ada dari hasil studi literatur. Siswa mencatat hasilnya pada Lembar Hasil untuk disimpan; (4) Guru menampilkan jawaban observasi (dalam slide powerpoint) yang berisi penjelasan ilmiah beserta berbagai konsepsi siswa. Siswa mendiskusikan konsepsinya sendiri dan memilih penjelasan yang terbaik; dan (5) Guru menuntun siswa membahas hasil demonstrasi dan diskusi yang dilakukan agar siswa memberikan penjelasan ilmiah sehingga lebih konsisten dan juga secara jelas menunjukkan apa miskonsepsinya dan kekurangan konsepsinya.

Demonstrasi pada ILD berorientasi CC memiliki dua jenis demonstrasi. Demonstrasi pertama untuk mengungkapkan kesalahan konsep siswa dan demonstrasi kedua untuk menstimulus konflik di dalam pemikiran siswa. Apabila jumlah kesalahan konsep saat demonstrasi awal berkurang pada saat demonstrasi kedua maka terdapat indikasi peningkatan pemahaman konsep pada siswa.

Indikator pemahaman konsep ialah apabila seseorang mampu menggunakan konsepnya dalam masalah dunia nyata. Seseorang akan mampu menjelaskan baik dalam bahasa ilmiah maupun dalam bahasa sehari-hari namun tetap sesuai konsep yang benar (Kurt, et.all, 2012).Orang yang paham konsep akan mampu menjelaskan apa makna dari konsep serta mampu menggunakannya. Konsep adalah gagasan umum/ ide siswa terhadap suatu objek/ kejadian.

Berdasarkan latar belakang masalah yang telah dikemukakan di atas, maka permasalahan penelitian ini dirumuskan dalam bentuk kalimat pertanyaan sebagai berikut.

Bagaimana perbandingan peningkatan pemahaman konsep antara siswa yang mendapatkan pembelajaran ILD berorientasi conceptual changedengan 
siswa yangmendapatkan pembelajaran ILD berorientasi common sense?

Bagaimana tanggapan siswa terhadap pembelajaran ILD berorientasi CC?

\section{METODE}

Penelitian ini merupakan penelitian kuasi eksperimen. Desain penelitian ini adalah metode kuasi eksperimen. Desain penelitian yang digunakan adalah pretest posttest group design. Populasi penelitian adalah seluruh kelas IX SMP di Kab. Pandeglang. Sampel penelitian dipilih dengan teknik purposive sampling sehingga diperoleh kelas IX B (kelas eksperimen) dan IX C (kelas Kontrol). Teknik ini dipilih karena terdapat pertimbangan tertentu yang diperhatikan misalnya siswa harus telah mempelajari konsep Hukum Newton.

Untuk mengukur pemahaman konsep siswa, digunakanlah soal pemahaman konsep berbentuk pilihan ganda. Soal ini diberikan sebagai pretest kemudian kelas diberikan treatment dan di akhir pertemuan dilakukan posttest.

Untuk mengetahui tanggapan siswa, maka digunakan tes skala sikap yang berisi tanggapan siswa terhadap pernyataanpernyataan yang berhubungan dengan pembelajaran dengan cara memberikan tanda centang.

Untuk mengetahui peningkatan pemahaman konsep, maka skor hasil pretest dan posttest diolah menggunakan persamaan $n$-gain:

$$
\langle g\rangle=\frac{s k o r_{\text {posttet }}-s k o r_{\text {pretest }}}{s k o r_{\text {maksimum }}-s k o r_{\text {pretest }}}
$$

(Hake, 1998)

Aspek pemahaman konsep yang diukur dalam penelitian ini adalah aspek interpretasi (menerjemahkan), aspek menjelaskan, aspek membandingkan, dan aspek menginferensi. Aspek ini dipilih karena disesuaikan dengan adaptasi langkah-langkah pembelajaran ILD berorientasi CC.

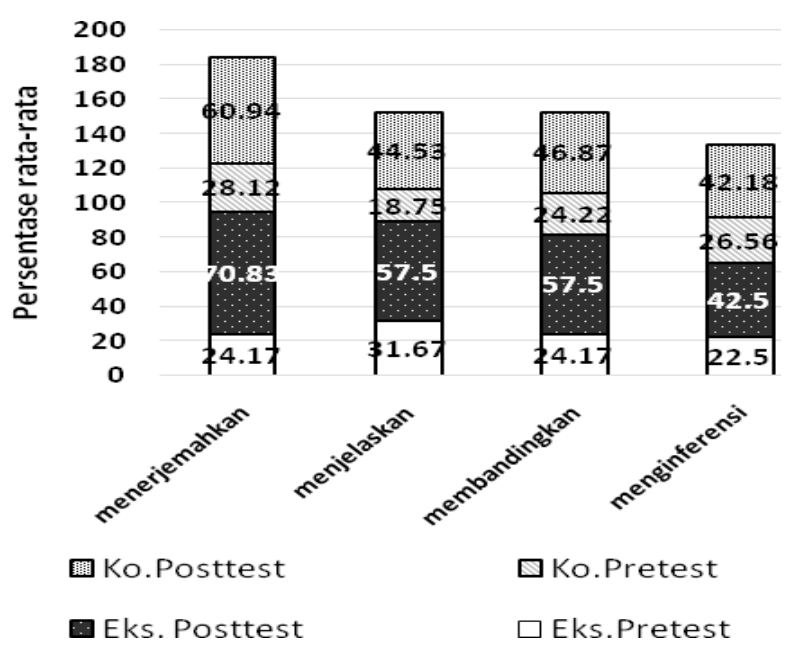

Gambar 1.

Peningkatan Aspek Pemahaman Konsep Kelas Eksperimen dan Kelas Kontrol.

Setelah diperoleh data $n$-gain baik pada kelas eksperimen maupun kelas kontrol, maka dilakukan uji homogenitas. Uji homogenitas dilakukan karena sampel lebih dari satu kelas sehingga perlu diketahui apakah kedua kelas sampel adalah dari sampel yang sama kemampuannya.

Setelah uji homogenitas,maka dilakukan uji normalitas. Hasil uji normalitas diperlukan sebagai pedoman untuk menguji hipotesis dengan uji statistik yang sesuai. 


\section{HASIL DAN PEMBAHASAN}

Berdasarkan analisis data, diperoleh data $n$-gain kelas eksperimen dan kelas kontrol, data homogenitas kelas eksperimen dan kelas kontrol, hasil uji normalitas kelas eksperimen dan kelas kontrol, dan hasil uji statistik.

Berdasarkan hasil penelitian menunjukkan bahwa terdapat peningkatan aspek pemahaman konsep siswa. Peningkatan aspek pemahaman konsep ditunjukkan oleh Gambar 1.

Berdasarkan Gambar 1 di atas, diketahui bahwa terjadi peningkatan persentase aspek pemahaman konsep pada kelas eksperimen dan kelas kontrol.

Aspek menerjemahkan. Pada saat pretest, persentase kelas eksperimen (24.17\%) lebih kecil dari persentase kelas kontrol (28.12\%). Aspek menjelaskan. Pada saat pretest, persentase rata-rata kelas eksperimen (31.67\%) lebih tinggi dibandingkan dengan persentase rata-rata kelas kontrol (18.75\%). Aspek membandingkan. Pada saat pretest, persentase rata-rata kelas eksperimen (24.17\%) lebih kecil dibandingkan dengan persentase rata-rata kelas kontrol yaitu sebesar (24.22\%). Aspek menginferensi. Pada saat pretest, persentase rata-rata kelas eksperimen $(22.5 \%)$ lebih rendah dibandingkan dengan persentase rat-rata kelas kontrol yaitu (26.56\%).

Pada saat pretest, aspek pemahaman konsep yang tertinggi pada kelas eksperimen adalah aspek menjelaskan sedangkan aspek pemahaman konsep yang tertinggi pada kelas kontrol adalah aspek menerjemahkan. Pada saat posttest, aspek pemahaman konsep yang tertinggi peningkatannya baik pada kelas eksperimen maupun kelas kontrol ialah aspek menerjemahkan.

Ditemukan pula bahwa pada saat pretest, persentase rata-rata aspek menerjemahkan, membandingkan, dan menginferensi pada kelas eksperimen lebih rendah dibandingkan persentase rata-rata kelas kontrol.

Hasil ini bukan menunjukkan bahwa kelas kontrol lebih baik dibandingkan dengan

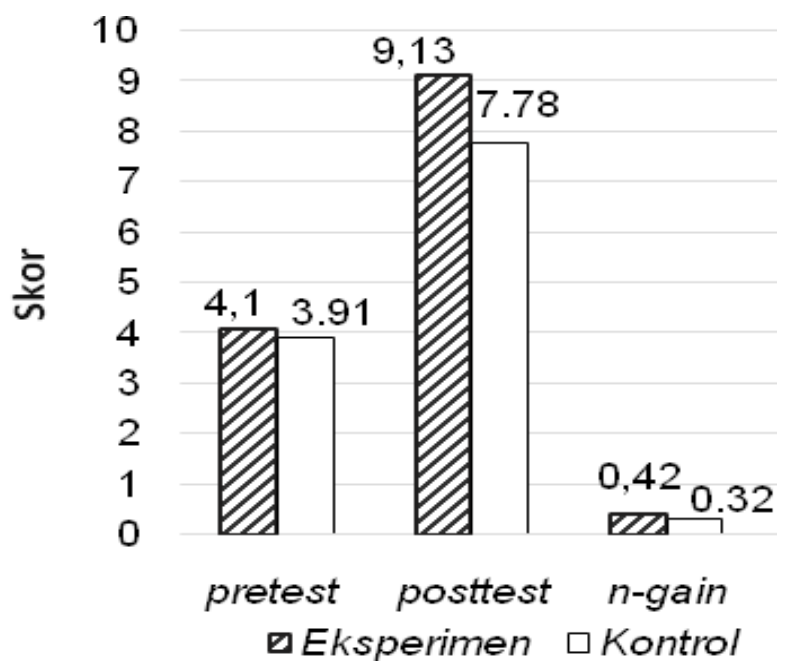

Gambar 2

Perbandingan Peningkatan Pemahaman Konsep Kelas Eksperimen dengan Kelas Kontrol

kelas eksperimen. Berdasarkan hasil analisis lembar konsepsi/ lembar prediksi dan lembar hasil, ditemukan bahwa siswa-siswa di kelas kontrol lebih banyak mengosongkan jawaban dibandingkan dengan siswa kelas eksperimen. Dengan kata lain siswa kurang terlibat dalam pembelajaran sehingga kinerja/ aktivitasnya rendah.

Ada beberapa faktor yang menyebabkan aktivitas siswa menjadi rendah misalnya karakteristik kinerja guru dan motivasi siswa tersebut. Karakteristik kinerja guru yang 
dimaksud antara lain kemampuan menyusun urutan kegiatan demonstrasi, kemampuan bertanya guru, kemampuan guru dalam memberikan feedback, serta ketersediaan waktu bertanya bagi siswa.

Sedangkan motivasi memiliki hubungan positif yang signifikan dengan kinerja siswa. Kinerja/ aktivitas siswa yang memiliki motivasi tinggi hasilnya lebih baik dibandingkan dengan siswa yang motivasinya rendah. Berkenaan dengan hal tersebut, motivasi yang positif cenderung menghasilkan prestasi yang baik pula (Albert,

Tabel 1.

Hasil Uji Homogenitas

\begin{tabular}{|c|c|c|c|c|}
\hline Kelas & Varian data & $\mathbf{F}_{h i}$ & $F_{\text {ta }}$ & Keputusan \\
\hline Eksperimen & 0,00453 & \multirow{2}{*}{1,096} & \multirow{2}{*}{4} & \multirow{2}{*}{ Homogen } \\
\hline Kontrol & 0,00413 & & & \\
\hline
\end{tabular}

hasil yang diperoleh siswa kelas eksperimen lebih baik dibandingkan dengan hasil yang diperoleh oleh siswa kelas kontrol. et.all., 2014). Oleh karena itu, kemungkinan siswa kelas kontrol menjawab dengan benar pertanyaan-pertanyaan dalam soal pemahaman konsep dengan cara menebak lebih besar dibandingkan dengan siswa di kelas eksperimen

Setelah dilakukan pretest, kedua kelas diberikansuatutreatmentberupapembelajaran ILD berorientasi CC untuk kelas eksperimen dan ILD berorientasi CS untuk kelas kontrol. Ternyata, posttest yang diberikan setelah treatment dilaksanakan menunjukkan bahwa

Agar peningkatan pemahaman konsep menjadi lebih jelas, maka data pada Gambar 1 diolah dan ditampilkan ke dalam bentuk

Tabel 2

Hasil Uji NormalitasKelas Eksperimen dan Kelas Kontrol

\begin{tabular}{cccc}
\hline Kelas & $\chi_{\text {hitung }}^{2}$ & $\chi_{\text {tabel }}^{2}$ & Kriteria Normalitas \\
\hline Eksperimen & 2.24 & 43.77 & Berdistribusi Normal \\
\hline Kontrol & 2.66 & 43.77 & Berdistribusi Normal \\
\hline
\end{tabular}

lain pada Gambar 2.

Pada Gambar 2, terlihat bahwa peningkatan pemahaman konsep kelas eksperimen lebih tinggi dibandingkan dengan pemahaman

Tabel 3

Hasil Uji-t Pemahaman Konsep

\begin{tabular}{llc}
\hline $\boldsymbol{t}_{\text {hitung }}$ & $\boldsymbol{t}_{\text {tabel }}$ & Kesimpulan \\
\hline 4,83 & 2,00 & Ha diterima \\
\hline
\end{tabular}

pada kelas kontrol dibuktikan dengan nilai $<\mathrm{g}>0.42$ untuk kelas eksperimen lebih besar dibandingkan dengan $<\mathrm{g}>0.32$ untuk kelas kontrol. Peningkatan pemahaman konsep termasuk kategori sedang.

Suatu demonstrasi yang melibatkan siswa akan berpengaruh lebih baik pada pemahaman konsep-konsep dasar Sebaliknya, apabila siswa pasif atau tidak terlibat maka proses penerimaan pengetahuan menjadi rendah (Svedružić, 2008). Siswa yang terlibat melalui pengamatan suatu proses atau fenomena dalam demonstrasi-demonstrasi akan lebih mudah memahami suatu materi. (Siswati, dkk., 2012).

Karena kedua kelas mengalami peningkatan pemahaman konsep, maka perlu dipilih kelas yang paling signifikan dalam peningkatan pemahaman konsep. Oleh karena itu, untuk mengetahui signifikansi perbedaan peningkatan pemahaman konsep, maka 
dilakukan uji statistik (uji-t).

Untuk mengetahui signifikansi perbedaan peningkatan pemahaman konsep pada kelas eksperimen dan kelas kontrol maka ada tahapan-tahapan yang dilakukan dimulai dari uji homogenitas, dilanjutkan uji normalitas, uji t-sepihak.

Tabel 1 menunjukkan hasil homogenitas antara kelas eksperimen dan kelas kontrol.

Setelah diperoleh hasil yang membuktikan bahwa kedua sampel adalah homogen maka dilanjutkan dengan uji normalitas data. Data normalitas diperoleh dengan mengolah $n$-gain kedua kelas. Hasil pengolahan data normalitas ditunjukkan pada Tabel 2.

Setelah diperoleh data normalitas, maka uji statistik yang dipakai adalah uji parametrik. Uji yang dipakai adalah uji-t satu pihak dengan taraf signifikansi 5\%. Hasil uji-t disajikan dalam Tabel 3.
Berdasarkan hasil uji-t pada Tabel3, diketahui bahwa peningkatan pemahaman konsep siswa yang mendapatkan pembelajaran ILD berorientasi CC lebih signifikan dibandingkan dengan peningkatan pemahaman konsep siswa yang mendapatkan pembelajaran ILD berorientasi CS.

Hasil temuan penelitian ini membuktikan bahwa keterlibatan siswa dalam ILD berpengaruh terhadap pemahaman konsep siswa. Keterlibatan siswa pada kelas eksperimen dilihat dari isian lembar Konsepsi, sedangkan pada kelas kontrol dilihat dari lembar Prediksi. Meskipun pemahaman konsep tidak ada yang mencapai ideal, pemahaman konsep siswa yang memperoleh pembelajaran melalui demonstrasi juga lebih baik. Tes skala sikap menunjukkan seluruh siswa memberikan tanggapan setuju bahwa pembelajaran ILD berorientasi CC dapat meningkatkan pemahaman konsepnya. Hasil ini dapat ditemukan pada Tabel 4.

Tabel 4

Rekapitulasi Tes Skala Sikap Pemahaman Konsep

\begin{tabular}{llrr}
\hline \multirow{2}{*}{ No } & \multirow{2}{*}{ Aspek } & \multicolumn{2}{c}{$\begin{array}{c}\text { Persentase tanggapan } \\
\text { Siswa (\%) }\end{array}$} \\
\cline { 3 - 4 } & \multicolumn{2}{c}{ S } & \multicolumn{1}{c}{ TS } \\
\hline 1 & Aspek Pemahaman Anderson & & \\
\hline$-\quad$ Menjelaskan & 96,67 & 3,33 \\
\hline$-\quad$ Menginterpretasi & 93,33 & 6,67 \\
\hline$-\quad$ Menginferensi & 90,00 & 10,00 \\
\hline$-\quad$ Membandingkan & 90,00 & 10,00 \\
\hline 2 & Pemahaman konsep & & \\
\hline & - Peningkatan Pemahaman Konsep & 100 & 0 \\
\hline
\end{tabular}

Berdasarkan hasil rekapitulasi tes skala sikap siswa pada Tabel 4, masih ada beberapa siswa yang masih kesulitan dalam menjelaskan, membandingkan, menginterpretasi, dan serta menginferensi.

Jika dihubungkan dengan hasil n-gain pemahaman konsep, maka dapat disimpulkan bahwa peningkatan pemahaman konsep pada kelas eksperimen tidak ada yang mencapai ideal meskipun peningkatan pemahaman konsep siswa pada kelas eksperimen lebih signifikan dibandingkan dengan peningkatan pemahaman konsep siswa kelas kontrol.

Siswa tetap memiliki pemahaman konsep yang lebih baik terhadap demonstrasi yang ditampilkan, meskipun tidak semua siswa mampu untuk menghubungkan konsepnya terhadap situasi baru. Situasi yang baru yang dimaksud adalah situasi yang ditampilkan pada demonstrasi konflik kognitif.(Mazzolini, dkk., 2010)

Berdasarkan Pada Tabel 4, seluruh siswa pada kelas eksperimen merasa mengalami 
peningkatan pemahaman konsep. Hasil ini diperoleh dengan melakukan analisis jawaban siswa pada soal pemahaman konsep yang menunjukkan bahwa lebih banyak jawaban soal pemahaman yang dijawab dengan benar pada saat posttest dibandingkan jumlah jawaban yang benar pada saat pretest. terjadi peningkatan pemahaman konsep.

\section{KESIMPULAN}

Peningkatan pemahaman konsep siswa yang mendapatkan pembelajaran ILD berorientasi CC lebih signifikan dibandingkan dengan peningkatan pemahaman konsep siswa yang mendapatkan pembelajaran ILD berorientasi CS. Dengan kata lain, skor rata-rata pemahaman konsep siswa kelas eksperimen lebih tinggi dibandingkan skor rata-rata pemahaman konsep siswa kelas kontrol.

Berdasarkan hasil analisis tes skala sikap siswa terhadap pembelajaran ILD berorientasi CC dapat disimpulkan bahwa sebanyak 96,67\% (29 siswa) merasamampu menjelaskan fenomena setelah demonstrasi yang dilakukan oleh guru, sebanyak 93.33\% (28 siswa)merasa mampu mengubah satu bentuk informasi ke bentuk informasi yang lain setelah demonstrasi yang dilakukan oleh guru, sebanyak 90\% (27 siswa) merasa lebih bisa membandingkan dua fenomena setelah demonstrasi yang dilakukan oleh guru, sebanyak 90\% (27 siswa) merasa lebih bisa menemukan pola hubungan antara dua konsep atau lebih setelah demonstrasi yang dilakukan oleh guru, dan sebanyak $100 \%$ (30 siswa) merasa pembelajaran dengan demonstrasi membuat mereka bisa mengerjakan soal fisika dengan jumlah benar yang lebih banyak dibandingkan dengan pembelajaran sebelumnya.

Berdasarkan hasil penelitian yangdiperoleh, peningkatan pemahaman konsep masih termasuk kategori sedang. Oleh karena itu, disarankan bagi peneliti selanjutnya untuk melakukan variasi atau kombinasi dengan metode lain misalnya demonstrasi dengan bantuan bahan bacaan, dengan diskusi, tayangan simulasi virtual yang interaktif.

Untuk meningkatkan aktivitas siswa, diharapkanguruberlatih dan mengembangkan kemampuan bertanya agar mampu menggali pengetahuan siswa.

Agar pemahaman konsep meningkat untuk semua aspek, maka sebaiknya guru meberikan bimbingan selama proses penjelasan materi sehingga apabila ada konsep yang keliru dapat langsung direvisi oleh guru.

\section{DAFTAR PUSTAKA}

Albert, Owino Ogutu., Osman, Ahmed., dan Yungungu, Alice. (2014). An investigation of Factors that Influence Performance in KCSE Biology in selected secondary schools in Nyakach District, Kisumu County, Kenya. Journal of Education and Human Development3(2): 957-977. Tersedia di http://aripd.org/journals/jehd/Vol_3 No 2 June 2014/58.pdf. Diakses pada 11 November 2014

Çepni, Salih., Şahin, Çiğdem, dan Ipek, Hava. (2010). Teaching Floating and Sinking Concepts With Different Methods and Techniques Based On The 5E Instructional Model. [Online]. AsiaPacific Forum on Science Learning and Teaching, Volume 11, Issue 2, Article 5. p.1 (Dec., 2010). Tersedia dihttp:// www.ied.edu.hk/apfslt/download/ v11 issue2 files/sahin.pdf. Diakses 18 November 2013.

Hake. 1998. Interactive-engagement versus traditional methods: A six-thousandstudent survey of mechanics test data for introductory physics courses. Department of Physics,Indiana University,Bloomington,Indiana

IschakS.W dan Warji.R. (1987). Program Remedial Dalam Proses Belajar Mengajar. Yogyakarta: Liberty

Joyce, Bruce; Weil, Marsha; and Calhoun, Emily. (2011). Models of Teaching. 
Yogyakarta: Pustaka Pelajar

Kurt, Sevil and Ayas, Alipasa. (2012).Improving Students' Understanding and Explaining Real Life Problems On Concepts of Reaction Rate By Using A Four Step Constructivist Approach. [Online]. Social and Educational StudiesVolume (issue) 4(2): 979-992. Tersedia di http://www.silascience. com/articles/10042012130442.pdf. Diakses pada 19 November 2013.

Mazzolini, AP; Edward, Thomas; O’Donoghue, Peter; Nopparatjamjomras. (2010). Using Interactive Lecture Demonstrations Student Learning in Electronics. [Online]. Proceeding AaeE Conference. Tersedia di http:// aaee.com.au/conferences/AAEE2010/ PDF/AUTHOR/AE100044.PDF. Di akses pada 6 Desember 2013.

Peraturan Menteri Pendidikan Nasional. (2006). Standar Isi untuk Satuan Dasar dan Menengah. Jakarta

Setyawan, Eko Juli. (2012). Implementasi Model Problem Based Learning dan Inkuiri Terbimbing untuk Meningkatkan Keterampilan Proses Sains dan Pemahaman Konsep Gelombang Siswa $S M P$. Tesis pada Prodi Pendidikan IPASPs UPI Bandung: tidak diterbitkan.

Siswati, Herekno Anen; Sunarno, Widha,; dan Suparmi. (2012). Pembelajaran Berbasis Masalah Dengan Menggunakan Metode Demonstrasi Diskusi dan Eksperimen Ditinjau Dari Kemampuan Verbal dan Gaya Belajar. [Online]. Jurnal Inkuiri Vol.1 (2):132-141. Tersedia di http://jurnal. pasca.uns.ac.id/index.php/ink/article/ view/129. Diakses pada 1 Februari 2014.

Suparno, Paul. (2012). Filsafat Konstruktivisme dalam Pendidikan. Yogyakarta: Kanisius

Svedružić, Antonio. (2008). Teaching Methodology of Physics. [Online]. Metodika 17:442-450. Tersedia di http://hrcak.srce.hr/file/55094. Diakses pada 3 November 2014

Wulandari, Widya and Nasrudin, Harun. (2013). Implementation Of 7-E Learning Cycle Model to Reduce Students' Misconceptions of Sub-Microscopic Level On Salt Hydrolysis In SMAN
1 Tarik Sidoarjo. UNESA Journal Of Chemical Education Vol.2 (20: 121-126. [Online]. Tersedia di http:// ejournal.unesa.ac.id/article/4794/36/ article.pdf. Diakses pada 5 juni 2013.

Zimrot, Rachel and Ashkenazi, Guy. (2007). Interactive Lecture Demonstrations: A Tool For Exploring and Enhancing Conceptual Change. [Online]. Chemistry Education Research and Practice (8) 2: 197-211. Tersedia di http://www.rsc.org/images/ Ashkenazi\%20paper2\%20final tcm1885042.pdf. Diakses pada 5 Desember 2013. 